\title{
What's Wrong with Modal Conceptions of Luck and Risk
}

\author{
Di Yang ${ }^{1}(1)$
}

Received: 9 August 2017 / Accepted: 9 May 2019 / Published online: 29 May 2019

(C) The Author(s) 2019

\begin{abstract}
The modal account of luck has become very popular and influential in the past decade. More recently, some of its proponents have also put forth a modal account of risk and argued that we ought to apply it to problems both in and out of philosophy. This paper tries to show that modal conceptions of luck and risk are mistaken.
\end{abstract}

\section{Introduction}

The modal account of luck has become very popular and influential in the past decade. More recently, some of its proponents have also put forth a modal account of risk and argued that we ought to apply it to problems both in and out of philosophy. ${ }^{1}$ Here, I try to show that such conceptions are mistaken. ${ }^{2}$ I start, in Sect. 2, by arguing that modal conceptions of luck are parasitic on the probability of the event in question. I clarify some key components of modal accounts of luck and show how such accounts ultimately reduce to probability. Then in Sect. 3, I consider some existing discussions surrounding so-called "lucky" true beliefs in lottery style scenarios. I argue that contrary to some modal theorists' suggestion, lottery scenarios do not show that luck is a modal notion. Finally, in Sect. 4, I turn to the modal account of

\footnotetext{
1 The most prominent proponent of modal accounts of luck and risk has been Duncan Pritchard, and I focus primarily on his articulation and defence of such accounts here. See also Whittington's manuscript on risk.

2 There has been a plethora of conceptual analyses on luck and risk within the past decade, partly due to the thought that such investigations will shed light on important questions in epistemology and other areas of philosophy. This kind of approach calls for a two-part solution to the problems of "luck" in philosophy. First, we need to understand the nature of luck. Second, equipped with such an understanding, we then specify the sense in which various philosophical issues (e.g. knowledge, responsibility, free will, etc.) are incompatible with luck. This paper is concerned with the first part of this project-i.e. the nature of luck. But see fn. 23 on why this approach may not be as useful as its proponents seem to believe.
}

Di Yang

d.yang-10@sms.ed.ac.uk

1 School of Philosophy, Psychology and Language Sciences, University of Edinburgh, Dugald Stewart Building, 3 Charles Street, Edinburgh EH8 9AD, UK 
risk. Here I argue that modal theorists have offered us no reason to be concerned about modal risk. Depending on the level of probabilistic risk in question, modal theorists' approach to risk assessment and reduction is either unnecessary or trivial.

\section{Probability Within the Modal Account of Luck}

Winning a fair lottery with long odds is a paradigmatic instance of luck. It is a matter of good luck if the win confers significant benefits upon the winner and it is a matter of bad luck if the "winner" has been selected to meet some dreaded fate. Most accounts of luck contain a significance condition such that an event is a matter of luck only if it is of some value for some specified being. ${ }^{3}$ In addition to a significance condition, different theories will account for luck with either a chanciness condition or a lack of control condition. Proponents of a lack of control account argue that matters of luck are significant events that are also beyond an agent's control. ${ }^{4}$ And those who endorse a chanciness account argue that matters of luck are significant events that are also in some specified sense unlikely to occur. This paper is not concerned with the significance condition or lack of control accounts of luck. The focus is on competing notions of chancinessi.e. on the differences between modal and probabilistic accounts of luck.

According to probabilistic accounts, lottery wins are matters of luck roughly because they are significant events that are probabilistically unlikely. ${ }^{5}$ The chances of winning a national lottery is so probabilistically farfetched and stacked against any given ticket that it is far more likely for one to lose than it is for one to win. Given different odds (e.g. 0.9), winning the lottery may not be considered a matter of luck—or it would be less of a matter of luck-because the event is more likely or almost guaranteed to occur.

When we talk about the probability of winning the lottery, we typically talk about objective chance rather than epistemic probability or subjective credence. Objective chance refers to features of the world and is independent of our beliefs about the event in question. ${ }^{6}$ In contrast, epistemic probability refers to the evidence we have in support of a particular proposition, whereas credence measures our degree of belief in a proposition irrespective of our evidence for that proposition. ${ }^{7}$ Our beliefs can track objective chance, but the objective probability of winning a national lottery is probabilistically farfetched regardless of our beliefs about its likelihood.

Modal accounts of luck appear to offer a different explanation for why some events are matters of luck, but the explanation do not differ, in essence, from the explanation offered by probabilistic accounts. Consider Pritchard's (2005) initial formulation of the modal condition on luck:

\footnotetext{
3 But see Pritchard (2014) who argues against the necessity of a significance condition.

4 Riggs (2009), Broncano-Berrocal (2015).

5 McKinnon (2013), Rescher (2014), Steglich-Peterson (2010).

6 In talking about objective probability, I make no commitments to any of the different interpretations of objective probability (e.g. frequency or propensity), though I will limit my discussion to the frequentist account.

7 See Hacking (2001, chapter 11), Mellor (2004, chapter 1).
} 
"If an event is lucky, then it is an event that occurs in the actual world but which does not occur in a wide class of nearest possible worlds where the relevant initial conditions for that event are the same as in the actual world." 8

To see why the modal account does not differ meaningfully from the probabilistic account of luck, we need to begin with a clear understanding of the modal condition on luck.

Crucially, two sub-conditions make up the modal condition on luck. The first subcondition has to do with the notion of modal distance, which concerns degrees of similarity between possible worlds and the actual world. Call this sub-condition ${ }_{\mathrm{D}}$. The second sub-condition has to do with the notion of modal frequency, which refers to the prevalence of an event across a specified set of close possible worlds.

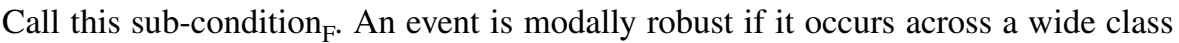
of specified close possible worlds, and it is modally fragile if it occurs across a limited number of specified close possible worlds. Together, sub-condition ${ }_{\mathrm{D}}$ and sub-

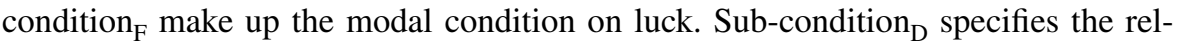
evant set of possible worlds that we are interested in (e.g. nearest possible worlds),

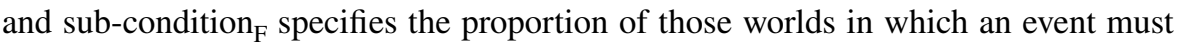
not occur (e.g. a wide class of those nearest possible worlds). On the modal account of luck, lottery wins are matters of luck because they are modally fragile across the set of possible worlds where we participate in the lottery.

Notice that the notion of modal distance (i.e. sub-condition ${ }_{\mathrm{D}}$ ), by itself, tells us nothing about luck. It simply measures the extent of the similarities between possible worlds and the actual world. ${ }^{9}$ For instance, a possible world in which the glass of water on my desk is five inches closer to me than it actually is at this moment is closer to the actual world than another possible world in which I am a barrister. And the possible world in which I am a barrister is closer than another possible world in which Edinburgh has switched places with Montreal. ${ }^{10}$ Both winning and losing the lottery are modally close events since not much has to change about the actual world in order to bring about the respective counterfactual events.

With respect to assessments of luck, the notion of modal distance is only relevant within sub-condition $_{\mathrm{D}}$, where we pick out a set of close possible worlds that are relevantly similar to the actual world. For instance, consider Pritchard's (2007b) later formulation of the modal condition, where "an event is lucky iff it obtains in the actual world but does not obtain in a wide class of near-by possible worlds". "The only difference between the 2005 and 2007 formulation is the relevant set of possible worlds that we need to specify-i.e. nearest vs. nearby possible worlds. Once we have picked a relevant set of possible worlds, we still need to apply sub-condition ${ }_{F}$ and assess whether an event is sufficiently infrequent across those possible worlds so as to count as a matter of luck.

\footnotetext{
8 Pritchard (2005, p. 128), my emphasis.

9 See Lewis (1979) for a discussion on the ordering of possible worlds.

10 Pritchard (2015, p. 443).

11 Pritchard (2007b, p. 279), my emphasis.
} 
Sub-condition $_{\mathrm{F}}$ is a key part of the modal condition on luck. Without it, a modal account would be over-inclusive. For instance, suppose an employer is hiring new employees on the basis of a lottery and John has been selected. The possible event of John not being selected is modally close. But the fact that the counterfactual event is modally close does not tell us anything about whether the actual event is a matter of luck. On a modal account of luck, it would be a matter of luck for John to be selected iff there is a sufficient number of close possible worlds where he is not selected (i.e. the event is modally fragile or infrequent). If five people are selected from a pool of one-hundred applicants, then presumably John has not been selected in a wide class of relevantly close possible worlds. However, if ninety-five people are selected from a pool of one-hundred applicants, then presumably John has been selected in a wide class of close possible worlds. This is exactly how a modal account of luck is able to explain lottery wins. What makes an instance of winning the lottery a matter of luck is not that the counterfactual event is modally close, but that there is a sufficient number of close possible worlds where the counterfactual event obtains instead. This is the concern of sub-condition ${ }_{\mathrm{F}}$; it specifies the frequency of the counterfactual event within a set of possible worlds. Without sub-condition ${ }_{\mathrm{F}}$, lottery losses would, counter-intuitively, be counted as matters of luck since the counterfactual event of winning the lottery is modally close.

There can, of course, be disagreements amongst modal theorists over the correct formulation of sub-condition $\mathrm{F}_{\mathrm{F}}$-i.e. the requisite modal frequency or fragility

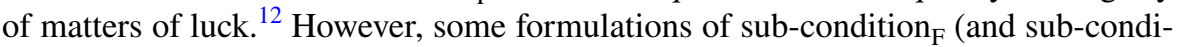
tion $_{\mathrm{D}}$ ) are clearly too vague and too wide to offer an accurate account. For instance, in Pritchard's latest (2014) articulation of the modal condition, he writes that "what makes an event lucky is that while it obtains in the actual world there are-keeping the initial conditions for that event fixed-close possible worlds in which this event does not obtain." 13 This formulation differs from earlier formulations in that the relevant set of close possible worlds (sub-condition $\mathrm{D}_{\mathrm{D}}$ ) has widened from nearest possible worlds (2005) to nearby possible worlds (2007b) to close possible worlds (2014). Additionally, the proportion of these possible worlds in which the actual event must not occur in order for the event to count as a matter of luck (sub-condition $_{\mathrm{F}}$ ) has narrowed from a wide class of nearest or nearby possible worlds (2005, 2007b) to presumably at least one or two close possible worlds (2014). The (2014) formulation of sub-condition $_{\mathrm{F}}$ is clearly too wide since on this formulation, not only are lottery wins a matter of luck, but lottery losses are also matters of luck, assuming there are one or two close possible worlds in which the losing ticket is the winner. ${ }^{14}$

\footnotetext{
12 See, e.g., Levy (2011) who argues that the requisite modal infrequency for matters of luck may differ depending on the significance of the event in question.

13 Pritchard (2014, p. 599).

14 Pritchard has suggested that all lottery events are a matter of luck, including lottery losses (personal communication, February 16, 2016). I think we should reject this suggestion. While we would not hesitate to use the language of luck to describe lottery wins, it would be odd to say to someone who has lost the lottery that his loss was a matter of (bad) luck. Of course, there can be negative lotteries, where a winner is selected to meet some dreaded fate. We would consider the "winner" of this lottery to be
} 
Notwithstanding any vague formulations of the modal condition on luck, the problem I want to raise is more fundamental and concerns sub-condition in $_{\text {in }}$ particular. Suppose modal theorists agree on the formulation of sub-condition ${ }_{D}$; i.e. a relevant set of close possible worlds from which to apply sub-condition ${ }_{\mathrm{F}}$. In order for modal theorists to offer an account that differs meaningfully from probabilistic accounts of luck, they need to explain how we can judge whether an event is modally (in)frequent without knowing the probability of that event. How can we judge whether an event obtains in any portion of relevantly close possible worlds if not by some kind of (implicit) reference to its probability? In other words, how can modal theorists apply sub-condition ${ }_{\mathrm{F}}$ without reference to probability?

For example, compare the following two lottery events. In the first lottery, six numbers are randomly drawn from a pool of 49 numbers. Any and all tickets that match all six numbers will win the jackpot. In the second lottery, only one number is randomly drawn from a pool of 49 numbers. Any and all tickets that match the selected number will win the same amount of money as the winner of the first lottery. ${ }^{15}$ Holding the value of the lottery prizes fixed, surely winning the first lottery is more of a matter of luck than winning the second lottery. Probability theorists about luck can explain this in terms of the probability of winning each lottery. It is more of a matter of luck to win the first lottery (where the probability of winning is 1 in 14 million) because, compared to the second lottery, the chances of winning are much lower, probabilistically speaking. But how might a modal theorist explain this without reference to, or knowledge of, the probability of winning each lottery? With respect to the second lottery, there is, presumably, a large portion of close possible worlds where the actual winners do not win the lottery. But, presumably, there is a substantially larger portion of close possible worlds where the actual winners of the first lottery do not win the lottery. Why should we not think that our judgements about modal frequency is inferred from and ultimately reduces to judgments about probabilistic likelihood ${ }^{16}$

The problem with modal accounts of luck is this. A descriptively accurate modal account must include sub-condition ${ }_{\mathrm{F}}$, otherwise the account would be over-inclusive. But it appears that our judgements about the modal frequency of events are

Footnote 14 (continued)

extremely unlucky, and we would also consider the "losers" of this lottery to be lucky. However, what explains this judgment is not that all lottery outcomes are a matter of luck, but that whether an outcome is a matter of luck also depends on the significance of the outcome in question.

15 We can assume that the winnings are fixed so the pot does not need to be split between multiple winners.

16 A reviewer has pointed out that this argument might be turned around. How can we determine the probability of $\mathrm{E}$ if not by appealing to modal considerations? For instance, on the classical interpretation of probability, the probability of $\mathrm{E}$ can be determined a priori by considering the range of possible outcomes, and what probability expresses is the proportion of equipossible outcomes that contain E. Why should we not think that probabilistic accounts of luck are parasitic on modality? One reason is that our judgments about luck are not limited to events where the probabilities are knowable a priori. We consider it a matter of good luck when an unreliable train reaches its destination on time, when a novice archer shoots a bullseye, or when a student aces her exams without studying. Such events are matters of good luck because they are infrequent, but the way we come to know that such events are infrequent is not through a priori reflections on the range of possible outcomes. 
guided by our judgments about probability. ${ }^{17}$ This is the sense in which the modal account of luck is parasitic on the probabilistic account of luck. What is wrong with modal accounts of luck is that we would not be able to apply sub-condition unless we already have some judgment about the probability of an event. But why should we not think that our judgements about probability are enough to tell us whether the event it is a matter of luck?

This challenge leads us back to sub-condition ${ }_{D}$-i.e. the need to specify a relevant set of possible worlds, which modal theorists could argue is crucial for accurate ascriptions of luck. Assuming that this is true, this line of argument still fails to differentiate a modal account from a probabilistic account in any meaningful way. Ironically, on some interpretations of probability, this step can make a modal account look more like a probabilistic account of luck. For instance, a popular interpretation of objective probability is frequentism, where probability expresses the frequency of an event relative to the size of a specified reference class. Modal theorists' concern with relevant sets of possible worlds resembles frequentists' attempt to situate events within appropriate reference classes. And when modal theorists disagree about which sets of possible worlds are relevant, their disagreements resemble disagreements between frequentists over the appropriateness of various reference classes.

For example, suppose we want to determine the extent to which finding a buried treasure is a matter of luck. Different modal calculations using different sets of possible worlds will yield different verdicts, just as different probabilistic calculations using different reference classes will yield different verdicts. If modal theorists only consider nearby possible worlds, where the treasure is buried in the same spot and where the subject digs for treasure in that spot, then the event would not be a matter of luck because it occurs in most of the specified worlds. But if we consider all possible worlds, including ones where the treasure has not been buried, then the event would be a matter of luck since it only occurs in a small portion of all possible worlds. ${ }^{18}$ Probabilistically speaking, if frequentists situate the event within the reference class of individuals who look for treasure in the particular spot where the treasure is buried, then we might think that the event is not a matter of luck since it has a probability of 1 . But if we situate the event within the reference class of all individuals (including those who have never looked for treasure), then we would get a significantly different verdict. And if we situate the event within the reference class of individuals who look for treasure on that island, we may get a different answer still.

So, on some interpretations of probability, the modal account of luck looks like a probabilistic account of luck in disguise, where the disguise comes from sub-condition $_{\mathrm{D}}$. But the question of how modal theorists can apply sub-condition $\mathrm{F}_{\mathrm{F}}$ without reference to probability is meant to reveal a fundamental problem for the modal

\footnotetext{
17 This is merely a claim about how we seem to make judgements regarding the modal frequency of an event. It does not point to any metaphysical thesis about the relationship between modal frequency and objective probability. The emphasis on judgments is also in keeping with the nature of luck as an inherently subjective phenomenon, which is wholly dependent on how competent speakers tend to use the concept.

18 See Carter and Peterson (2017) who argue that the modal account should consider events across all possible worlds.
} 
account of luck. If modal theorists must rely on probability judgments in order to apply half of their account (while the other half of their account can arguably be accommodated by some versions of a probabilistic account), then it is unclear why we need a modal account of luck at all, especially when probabilistic accounts are more intuitive and easier to apply.

\section{Lottery Propositions and the Modal Account of Luck}

In response to my line of criticism, Pritchard points to one instance of luck in particular which he claims can only be accounted for by a modal conception of luck. Suppose a subject has purchased a ticket to a fair lottery with long odds-fourteen million to one. The draw has been made but the subject has not heard the winning numbers and so has no idea whether her ticket is a winner or a loser. In one variation of this scenario, the subject knows the odds of winning this lottery and on this basis forms the (accidentally) true belief that her ticket is a loser. In a second variation, the subject does not know the odds but reads the winning numbers in a reliable newspaper and thereby forms the true belief that her ticket is a loser. ${ }^{19}$ Here, Pritchard's argument for the modal account of luck goes as follows:

(1) The first subject does not know that her ticket is a loser.

(2) The first subject does not have knowledge because her belief is true as a matter of luck. ${ }^{20}$

(3) A modal account of luck counts the first subject's true belief as a matter of luck.

(4) A probabilistic account of luck does not count the first subject's true belief as a matter of luck.

(5) Therefore, luck is a modal (rather than probabilistic) notion. ${ }^{21}$

The soundness of this argument depends on premise (2). It depends on whether subject one's true belief is a matter of luck, and I will show that it is not.

To see why it is not an instance of luck, we need to begin by separating questions about luck from questions about knowledge. The intuition we are supposed to have in this scenario is that the first subject does not possess knowledge whereas the second subject does. What makes our judgments about these two subjects puzzling, allegedly, is that probabilistically speaking, it is extremely likely for the first subject to form the true belief that she has lost the lottery and yet we do not think she possesses knowledge. On the contrary, assuming that even reliable newspapers are subject to misprints, it is less likely, probabilistically speaking, for the second subject to form the true belief that she has lost the lottery, and yet we think she does possess knowledge. If our intuitions are correct, it would seem that knowledge is not merely

\footnotetext{
19 Pritchard (2014, p. 596).

20 Ibid.

21 Ibid., pp. 596-8.
} 
"a straightforward function of the strength of one's evidence, probabilistically conceived". ${ }^{22}$ So far, so good.

Now, we must note that our judgments about knowledge should not affect our judgments about luck. If a subject does not possess knowledge, it does not necessarily mean that the truth of her belief is a genuine matter of luck. Surely, our judgments about luck should be made independently of our judgments about knowledge. This point concerns a broader issue that is relevant to those who discuss luck in relation to other philosophical questions. Pritchard, for instance, undertook an analysis of luck with the aim of developing a theory of knowledge known as anti-luck epistemology. According to him, the first step in developing such a theory is to offer an account of luck; that is, a descriptively accurate, metaphysical account of the phenomenon of luck. Equipped with such an account, the next steps are to specify the sense in which luck is incompatible with knowledge, and to develop an anti-luck condition on knowledge that captures this specific incompatibility. ${ }^{23}$

If, like Pritchard, one's aim is to offer a descriptively accurate account of luck before using it to better understand knowledge, then the first step of doing conceptual analysis on luck must be an isolated inquiry, independent of our preconceived understanding that some conditions might be incompatible with knowledge. This is to ensure that said conditions do not end up in our account of luck unless they are genuine defining features of luck. For example, suppose knowledge is incompatible with the truth of one's belief being an accident. Whether the quality of [being an accident] is a feature of luck is a question that must be addressed independently of considerations relating to its incompatibility with knowledge. Otherwise, we risk assuming a specific notion of the phenomenon of which we are trying to give a descriptively accurate account.

With this in mind, we can turn to the issue of luck. Unlike the paradigm case of luck I discussed earlier - that of [winning a fair lottery with long odds]-here, the matter in question is [the truth of a subject's belief] with respect to her ticket. ${ }^{24}$ Intuitively, we think [winning a fair lottery] is a genuine matter of luck, but do we

\footnotetext{
22 Ibid., p. 596.

23 Ibid., pp. 594-5. Note that, at best, this approach can only form a small part of a much bigger philosophical inquiry. Before anyone offered an analysis of the concept of "luck", philosophers were using "luck" rather loosely in debates about knowledge, justice, free will, and responsibility. In these debates, philosophers were not necessarily talking about genuine matters of luck, but rather using "luck" to denote a wide range of conditions such as accidents, chance occurrences, fortunate circumstances, lack of control, etc. Some or all of these conditions are thought to be in some sense incompatible with knowledge, justice, free will, or responsibility. But insofar as these conditions can be (and have been) differentiated from luck, the focus on finding a descriptive account of luck has ruled out these conditions from the philosophical discussion. Consequently, those who attempt to understand the nature of luck before using it to investigate why luck is incompatible with knowledge, justice, free, or responsibility, are at best only addressing a small part of the question. Their theory cannot amount to an adequate explanation because they do not explain why knowledge, justice, free will, or responsibility is sometimes also incompatible with accidents, chance, fortune, lack of control, etc. If this criticism is valid, then we should likewise be careful about the emergence of anti-risk theories of knowledge, which employ the same approach as its anti-luck predecessors.

24 Pritchard (2007a, p. 30): "the core worry about luck as regards knowledge possession relates to luck in the truth of the relevant belief".
} 
really think that about [the truth of subject one's belief]? Pritchard seems to think so, and some epistemologists might readily agree. But why should we think this? Obviously, the answer cannot be because her belief could have easily been false, or that her belief is false in a sufficient portion of relevantly nearby possible worlds. This response merely presupposes the modal account of luck that is under scrutiny. In order for Pritchard's argument to be sound, what is meant by "luck" in premise (2) must reflect an ordinary or colloquial understanding of the term luck. This is because (our understanding of) the nature of luck is tied to how we would ordinarily use the concept.

Here is the fallacy in Pritchard's argument. On the one hand, the meaning of "luck" that is familiar to epistemologists is that some characteristics of the subject's belief formation process is incompatible with knowledge. On the other hand, the ordinary or colloquial meaning of "luck" is not necessarily equivalent to whatever characteristics that make a true belief incompatible with knowledge. In arguing for his modal account of luck, Pritchard equivocates on these two different meanings. The conclusion in (5) concerns an ordinary, colloquial notion of luck because Pritchard's account is meant to be a descriptively accurate account of the phenomenon. But the notion of luck that is in play in premise (2) is not an ordinary, colloquial notion. There, "luck" is a stipulated term, which merely conforms to epistemologists' rough understanding of the concept prior to any conceptual analysis. Subject one's true belief is a matter of luck merely in the sense that her belief is true in some way that is incompatible with knowledge. Outside of some discussions in contemporary epistemology, we would not ordinarily describe subject one's true belief as a matter of luck. ${ }^{25}$ For instance, consider this parallel example.

Suppose I possess a big book of Edinburgh phone numbers. The book lists phone numbers from Edinburgh only, without any indication as to whom each number belongs. Suppose I randomly select a number from this book and try to determine whether it belongs to Pritchard. Given that this book contains hundreds of thousands of phone numbers, the likelihood that I just happen to have selected Pritchard's number is probabilistically unlikely, though modally close. Based on the probability alone, I form the belief that I have not selected Pritchard's number. If my belief turns out to be true, we would not say that my true belief is a matter of luck. For why would we say such a thing? What else should we expect? Given the odds, we should

\footnotetext{
25 To make the point about equivocation clearer, consider how "luck" has been treated in discussions about legal responsibility. For legal philosophers, "luck" is a stipulated term, used to designate an agent's lack of (some sense of) control over an outcome. It is specifically lack of control-as opposed to any other characteristics of luck - that is thought to be incompatible with responsibility. When an incompetent shooter tries but fails to cause harm, legal theorists might describe his failure as a matter of luck because he lacks adequate control over his shot. But just because legal theorists would describe the failed attempt as a matter of luck does not necessarily mean that it really was a matter of luck. For instance, if the probabilistic account of luck is right, then the failed attempt is not a matter of luck because the likelihood of failure is quite high for an incompetent shooter. We cannot simply take legal theorists' use of the term "luck" as evidence for luck in the ordinary, colloquial sense of the term. See, e.g., Moore (1994, 2009) who thinks the problem of moral luck would be better cast in terms of causation.
} 
expect my belief to be true. ${ }^{26}$ On the other hand, if my belief turns out to be false, that I have in fact selected Pritchard's number, then we would say that my belief is a matter of (bad) luck. And it would be appropriate to say such a thing, given that it was extremely unlikely for my belief to be false.

The same thing can be said about subject one's belief in the lottery ticket scenario. Why should we say that her true belief is a matter of luck when that is exactly what we should expect? ${ }^{27}$ Pritchard's methodology, one of taking ordinary ascriptions of luck to be good evidence for the phenomenon, can get us a descriptively accurate account of luck only when the ascription is in fact an ordinary or colloquial ascription. The lottery ticket scenario is a paradigmatic instance where the acquisition of a true belief is incompatible with knowledge, and it is appropriate for epistemologists to say that "subject one's true belief is a matter of luck" if "luck" is used as a stipulated term. But we cannot take epistemologists' use of "luck" as evidence for the nature of luck. At best, what we can say about subject one's true belief is that reasonable people can disagree about whether it is an instance of luck. However, if subject one's true belief is not an instance of luck, then what the lottery ticket scenario illustrates, contrary to Pritchard's claim, is not that luck is a distinctively modal notion. What it illustrates is that the probabilistic account of luck gets us the right result here precisely because it does not count subject one's true belief as a matter of luck. ${ }^{28}$

\section{What's Wrong with Modal Conceptions of Risk}

Recently, modal theorists about luck have turned their attention to risk, and anti-luck theories of epistemology have turned into anti-risk epistemology. This transition is partly motivated by the suggestion that luck and risk are essentially the same concept, except judgments about luck are made ex post while risk assessments are made ex ante. ${ }^{29}$ If this suggestion is sensible, it is sensible to the extent that the matter of luck in question involves some degree of risk. However, since matters of luck do not always involve risk-e.g. finding money on the side of the road-at best, we can only get a partial understanding of luck from an account of risk. ${ }^{30}$ In the rest of this paper, I will show that a modal approach to risk assessment and reduction is either

\footnotetext{
${ }^{26}$ See, e.g., Rescher (2001, pp. 24-8) who characterizes matters of luck as matters that we could not have rationally expected to occur.

27 It might be the case that in this type of situation, we would actually say that the subject's true belief is a matter of luck. But even if we do say such a thing, I am skeptical that the ascription of luck here is really attributable to the closeness of the counterfactual event. Instead, I think we consider subject one's true belief to be lucky because we attach (whether explicitly or implicitly) some kind of significance to true beliefs.

28 Of course, according to earlier formulations of the modal account, the truth of subject one's belief would also not be considered a matter of luck since her belief would be true in a wide range of nearby possible worlds.

29 Coffman (2007), Pritchard (2014, 2015, 2016), Broncano-Berrocal (2015).

${ }^{30}$ Of course, there is a chance that the subject will walk on without spotting the money on the sidewalk, but it is a stretch to say there is a risk that she will not spot the money.
} 
unnecessary or trivial. Before I explain why this is the case, I want to highlight a difficulty for modal theorists who think we can understand luck in terms of risk and vice versa.

Recall that the modal condition on luck has two sub-conditions: sub-condition $\mathrm{D}_{\mathrm{D}}$ and sub-condition ${ }_{\mathrm{F}}$. The modal account of risk, however, appears to include only sub-condition $_{\mathrm{D}}$. According to Pritchard, there is a high risk that a potential negative event $\mathrm{E}$ will occur if $\mathrm{E}$ is modally close, and there is a low risk if $\mathrm{E}$ is modally far off. ${ }^{31}$ The notion of modal frequency is missing from this formulation of risk, where modal distance alone is meant to tell us whether or not E is risky. Earlier, I argued that the frequency condition is indispensable to a modal account of luck because the account would be over-inclusive without it. But if the frequency condition is not essential to a modal account of risk, then it is unclear how modal conceptions of luck and risk are related to each other.

Modal theorists can either amend the modal condition on risk to include a subcondition $_{\mathrm{F}}$, or forfeit their claim that luck and risk are basically the same concept. The first option would make their account of risk vulnerable to the same criticism I levied against the modal account of luck-i.e. their account would be parasitic on a probabilistic account of risk. The second option allows the modal account of risk to remain as it is, where degrees of risk are measured in terms of modal distances. I will explore the second option here since it deals with the modal account of risk as it has been formulated by its proponents. As we will see, depending on the level of probabilistic risk involved, the modal approach to risk assessment and reduction is either unnecessary or trivial.

To begin, we can understand the modal account of risk by contrasting it with the familiar probabilistic way of thinking about risk. Typically, we understand and express degrees of risk in terms of our evidential probability. A potential unwanted event $\mathrm{E}$ carries a high risk if its probability is close to 1 , and $\mathrm{E}$ carries a low risk if its probability is close to 0 . For instance, the risk of being selected to meet some dreaded fate in a typical national lottery style lottery is very low, at roughly one in fourteen million. In contrast, the risk of losing a typical national lottery is very high, at roughly close to one. For modal theorists, the risk of E does not depend (solely) on its probability but also on its modal distance to the actual world. ${ }^{32} \mathrm{E}$ is a high risk event if it is modally close, and it is a low risk event if it is modally far off. Accordingly, all lottery events are high risk events for modal theorists since not much has to change about the actual world in order for a winner to become a loser and vice versa.

In many cases, probabilistic likelihood will match modal distance, but probability and modality can come apart. Here are the possibilities:

(1) E is probabilistically unlikely but modally close (e.g. being selected in a national lottery)

(2) E is probabilistically unlikely and modally far off ${ }^{33}$

${ }^{31}$ Pritchard (2016, p. 563).

${ }^{32}$ See fn. 38.

${ }^{33}$ See Pritchard (2015) for his examples of scenarios (1) and (2). 
(3) E is probabilistically likely and modally close (e.g. not being selected in a national lottery)

(4) E is probabilistically likely but modally far off

I will discuss scenarios (1) and (2) before turning to (3) and (4).

If we are following probability, we will think that the risk of $E$ is extremely low in both (1) and (2). Modal theorists, on the other hand, claim that the risk in (1) is much higher because the event is modally close and, in that sense, could easily occur. The probability of E can be identical across (1) and (2), but modal theorists would still believe we should be more worried about scenario (1). ${ }^{34}$ Note that modal theorists are advancing two theses here. First, there is a descriptive thesis regarding our judgements about risk. Here, modal theorists believe we judge (1) to be more risky than (2), and that generally speaking, our judgements about risk tend to track counterfactual closeness rather than probability. ${ }^{35}$ Second, there is a normative thesis about what we should do. Modal theorists tell us we should be significantly more concerned about (1) than about (2), and that we should add safeguards to (1) in order to make E modally far off.

For the purpose of this paper, I will assume that the descriptive thesis is true. The problem I want to raise for modal theorists concerns their normative thesis. In scenario (1), where the probabilistic risk is low, it is unnecessary for us to make E modally far off. There is no need for us to make (1) look more like (2) because it is unclear why we should be concerned with the modal distance of a risk event. Probability expresses the frequency with which we can expect $\mathrm{E}$ to occur. And if $\mathrm{E}$ is sufficiently infrequent, why should we care that $\mathrm{E}$ is modally close? For modal theorists, a modally close event is one that could easily occur. But for those who are inclined to follow probability, the counterfactual language in the modal account of risk in unpersuasive. After all, in a perfect world, if we conduct the lottery fourteen million times, only one of those fourteen million draws will result in an explosion.

In response to this point, modal theorists will often refer back to their descriptive claim and reiterate the point that people do in fact care about counterfactual closeness in their judgements about risk. But given that the descriptive claim is simply about people's perception of risk, it cannot lend any support to the normative thesis. The mere fact that we tend to follow modality in our judgements about risk does not show that we should follow modality. ${ }^{36}$ In fact, what is interesting about the

\footnotetext{
34 Pritchard (2015, p. 441-2).

35 Pritchard (2015, p. 444-8). Note that Pritchard makes an additional and much stronger claim, which is that (1) is in fact more risky than (2).

36 A reviewer has pointed out that given the discussion in Sect. 3, we might want to note the relevance of ordinary judgements to our understanding of luck and risk. Earlier I rejected Pritchard's argument for the modal account of luck on the basis that we would not consider subject one's true belief about her lottery ticket to be a matter of luck in the ordinary, colloquial sense of the term. But in this section, I am rejecting the relevance of ordinary people's judgments for how we should understand risk. There is no tension between using ordinary judgments to understand luck while rejecting such judgments for risk. The difference between luck and risk is that luck does not typically have implications for how we should act. Additionally, it is not obvious there is anything more to luck than how we ordinarily understand and use the concept. On the other hand, we are primarily interested in risk because we want to understand how
} 
descriptive thesis is precisely the suggestion that people tend to ignore probability, a framework which we think is efficacious and should be followed. Until modal theorists offer a better explanation for why we should care about counterfactual closeness in our risk assessments, we have no reason to think that scenario (1) is more risky than scenario (2). And until modal theorists explain why (1) is more risky than (2), it is unnecessary to try to make (1) look more like (2), especially when the probability of $\mathrm{E}$ is already very low.

We can now consider scenarios (3) and (4), where the initial risk is high probabilistically speaking.

(3) E is probabilistically likely and modally close (e.g. not being selected in a national lottery)

(4) E is probabilistically likely and modally far off. ${ }^{37}$

Here, probability theorists and modal theorists would agree that the level of risk is high in both (3) and (4). Modal theorists may argue that we should be concerned with the modal distance of a risk event, but they do not argue we should therefore disregard probability. ${ }^{38}$ If the probability of E is identical across (3) and (4), a modal theorist would argue that (4) is less risky than (3), but given that E is probabilistically likely, we would still want to reduce the probabilistic risk involved in both (3) and (4).

To reduce the risk in (3) and (4), probability theorists would implement safeguards to reduce the probability of E. Presumably, modal theorists would agree with this, except they would also implement safeguards to make E modally far off. As I mentioned earlier, modal closeness will often match probabilistic likelihood so that when we decrease the modal risk of $\mathrm{E}$, we also decrease its probabilistic likelihood. However, modal risk and probabilistic risk may go in different directions. To see why the modal approach to risk reduction is trivial, consider the following options:

(a) We can increase modal risk and decrease probabilistic risk.

(b) We can decrease modal risk and increase probabilistic risk.

(c) We can decrease modal risk and decrease probabilistic risk.

\footnotetext{
Footnote 36 (continued)

we should act under uncertainty. We would not want to rely on lay people's judgments about risk because they are often imprecise, mistaken, and thus not very useful in guiding our actions.

37 An example of (4) might look as follows. Suppose a bomb will go off in a city if the majority of its residents take a different route to work tomorrow. Unbeknownst to everyone, the information regarding the bomb has been miscommunicated and the residents are under the impression that the bomb will go off unless most people take a different route to work. There is no way to correct this misunderstanding. The probability that most people will take a different route is high since they do not want the bomb to explode. But this scenario is modally far off since, presumably, a great deal would have to change in order for most people to take a different route to work.

38 See Pritchard (2015, p. 449), Whittington (2017, p. 13).
} 
It might look as if we ought to favour option (c) since it decreases both modal and probabilistic risks. But which option we implement should surely depend on the extent to which probabilistic risk can be reduced.

Suppose the initial probability of E is 0.7 , and suppose that options (a), (b), and (c) will bring the probability of $E$ to $0.5,0.9$, and 0.1 respectively. Under option (b), we would implement a number of safeguards, all of which would have to fail in order for $\mathrm{E}$ to occur, but the probability of failure is quite high. Surely, this would offer us no comfort. Between options (a) and (c), it seems quite clear that we should favour (c). Of course, option (a) would involve implementing something like a lottery-style safeguard, where E would only occur if a certain set of numbers came up in the national lottery. This makes E a very close possibility. But surely this has nothing to do with why we would favour option (c). We would go with (c) because it is more effective at reducing probabilistic risk than (a), regardless of its effect on modal risk. If we modified option (a) so that it now reduced the probability of $E$ to 0.0001 , then we ought to favour (a), even if it means implementing a lottery style system. In situations where the initial (probabilistic) risk is high, the modal approach to risk reduction is trivial because our decisions are ultimately guided by probability rather than the modal distance of a risk event. ${ }^{39}$

This raises a question for modal theorists. They believe that the modal approach to risk assessment and reduction should supplement the probabilistic conception of risk, but how is this to be done in practice? ${ }^{40}$ Counterfactual reasoning certainly plays a key role in our judgments and deliberations, but it rarely plays a decisive role. Modal theorists have argued that if the probability of a risk event is identical across two scenarios, then the notion of modal closeness is able to determine which scenario poses a greater risk. Their approach seems to get the deliberative process backwards. ${ }^{41}$ In practice, we often use counterfactual reasoning to identify several options-i.e. we think about what could happen if we did such and such. We think about different preventive measures that can be adopted in order to create a situation where the risk event would not easily occur. However, aside from policy considerations, whether we choose to adopt any of these measures ultimately depends (and should depend) on whether the measure is effective at reducing the probability of the risk event. Counterfactual thinking might help us identify possible measures to adopt, but modal considerations should not be the final arbiter when it comes to adopting any such measures.

\footnotetext{
39 This is not a knockdown argument against the modal account of risk. Modal theorists can concede that since the decrease in probabilistic risk is so significant, we can favour modified option (a) without having to abandon the modal account of risk. After all, the modal account does not rule out the importance of probability. What this means though is that modal theorists need to give an account of when modality matters, and the extent to which modal risk matters more than probabilistic risk. At what point is a decrease in probabilistic risk sufficient for us to ignore modal risk, and at what point is a decrease in modal risk sufficient for us to ignore probabilistic risk?

40 See fn. 38.

41 Thanks to Rosa Hardt for this point.
} 
Acknowledgements I am grateful to Andrew Cornford, Antony Duff, Duncan Pritchard, Martin Smith, Ben Sworn, and Lee Whittington for their helpful comments on previous drafts of this paper, and to Adam Carter, Ana-Maria Cretu, Giada Fratantonio, and Rosa Hardt for their discussions. This paper also benefited greatly from comments and suggestions made by two anonymous referees of this journal. I am very thankful for their input.

Open Access This article is distributed under the terms of the Creative Commons Attribution 4.0 International License (http://creativecommons.org/licenses/by/4.0/), which permits unrestricted use, distribution, and reproduction in any medium, provided you give appropriate credit to the original author(s) and the source, provide a link to the Creative Commons license, and indicate if changes were made.

\section{References}

Broncano-Berrocal, F. (2015). Luck as risk and the lack of control account of luck. Metaphilosophy, 46, $1-25$.

Carter, J. A., \& Peterson, M. (2017). The modal account of luck revisited. Synthese, 194, 2175-2184.

Coffman, E. J. (2007). Thinking about luck. Synthese, 158, 385-398.

Hacking, I. (2001). An introduction to probability and inductive logic. Cambridge: Cambridge University Press.

Levy, N. (2011). Hard luck: How luck undermines free will and moral responsibility. Oxford: Oxord University Press.

Lewis, D. K. (1979). Counterfactual dependence and time's arrow. Nô̂s, 13, 455-476.

McKinnon, R. (2013). Getting luck properly under control. Metaphilosophy, 45, 558-577.

Mellor, D. H. (2004). Probability: A philosophical introduction. New York: Routledge.

Moore, M. S. (1994). The independent moral significance of wrongdoing. Journal of Contemporary Legal Issues, 5, 237-281.

Moore, M. S. (2009). Causation and responsibility: An essay in law, morals, and metaphysics. Oxford: Oxford University Press.

Pritchard, D. (2005). Epistemic luck. Oxford: Oxford University Press.

Pritchard, D. (2007a). Knowledge, luck and lotteries. In D. H. Pritchard \& V. Hendricks (Eds.), New waves in epistemology. London: Palgrave Macmillan.

Pritchard, D. (2007b). Anti-luck epistemology. Synthese, 158, 277-297.

Pritchard, D. (2014). The modal account of luck. Metaphilosophy, 45, 594-619.

Pritchard, D. (2015). Risk. Metaphilosophy, 46, 436-461.

Pritchard, D. (2016). Epistemic risk. The Journal of Philosophy, 113, 550-571.

Rescher, N. (2001). Luck: The brilliant randomness of everyday life. Pittsburgh: University of Pittsburgh Press.

Rescher, N. (2014). The machinations of luck. Metaphilosophy, 45, 620-626.

Riggs, W. (2009). Knowledge, luck, and control. In A. Haddock, A. Millar, \& D. Pritchard (Eds.), Epistemic value. Oxford: Oxford University Press.

Steglich-Petersen, A. (2010). Luck as an epistemic notion. Synthese, 176, 361-377.

Whittington, L. J. (2017). Counterfactual chanciness and risk: Giving possibility a chance. Unpublished MS.

Publisher's Note Springer Nature remains neutral with regard to jurisdictional claims in published maps and institutional affiliations. 